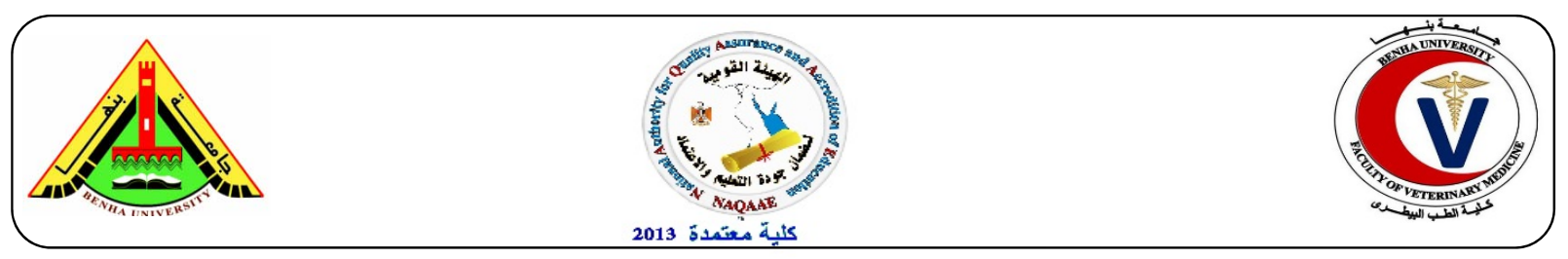

\title{
Characterization of Methicillin Resistance Staphylococcus aureus isolated from chicken and human
}

\author{
${ }^{1}$ Ashraf, A. Abd El-Tawab , ${ }^{1}$ Fatma, I.Hofy , ${ }^{2}$ Sahar, R. Mohamed , ${ }^{3}$ Sohila, H. Amin \\ ${ }^{1}$ Bacteriology, Immunology and Mycology Dep., Fac. of Vet. Med., Benha Univ., ${ }^{2}$ Bacteriology Department, Animal \\ Health Research Institue, Doki, Giza.
}

\section{A B S T R A C T}

Staphylococcus aureus causes a wide range of diseases in human beings, from minor skin infections to severe illnesses such as septicemia, toxic shock, endocarditis, and pneumonia. Staphylococcus aureus is a major pathogen of increasing importance due to the rise in antibiotic resistance. S. aureus was an important cause of disease in poultry it could be involved in a wide range of clinical conditions such as septicemia, bone and Joint infections, abscesses and dermatitis.In this study, 160 samples were collected, out of which 80 samples were from poultry and human patients ( 80 for each ). The incidence of infection with S.aureus in Bumble foot, Skin swabs in chicken and Diabetic foot swab, Skin sawb and Nasal swab in human were, $10 \%, 66 \%, 30 \%, 40 \%, 67.5 \%$ respectively. Methicillin resistant S. aureus (MRSA) were incidence in chicken and human $66.6 \%$ and $33.3 \%$ respectively. Subjected to PCR for detection of some antimicrobial resistance genes using intrinsic methicillin resistant gene (mec A), the IgG binding region of protein A(spa) gene were $83.3 \%$ and $50 \%$ respectively also beta-lactamase (blaZ) gene $100 \%$ and $100 \%$ respectively were detected in most $M R S A$ isolates either from human or chicken samples.

Keywords: Methicillin resistant - S.aureus - human - chicken - mec A gene - blaZ gene -spa gene

(http://www.bvmj.bu.edu.eg)

(BVMJ-32(1): 132-137, 2017)

\section{INTRODUCTION}

Methicillin resistant Staphylococcus aureus MRSA has been found to colonize livestock including pigs, cattle and poultry. Since many Of the MRSA clone allineages identified in livestock were un-Common for methicillin-resistant staphylococcus aureus (MRSA) isolates found until then in human hosts, the term "livestockassociated MRSA',(LA-MRSA) has been introduced to distinguish these MRSA from classical human hospital-acquired (HA-MRSA) or community-associated MRSA(CA-MRSA). (Köck et al., 2013). In poultry, S. aureus is associated with many clinical syndromes including tenosynovitis, omphalitis, femoral head necrosis, infected hock and stifle joints secondary to coccidiosis and "bumble foot" (Ashraf A Abd El Tawab1, 2015; Suleiman et al., 2013). Susceptibility testing results for all $275 \mathrm{~S}$. aureus isolates were consistent with cefoxitin screening and mecA gene PCR. (Shan et al., 2016). Further $S$. aureus is Gram positive producing smooth, circular colonies, convex and clustrous; size of the colony may be $0.5-1.5 \mu \mathrm{m}$ in diameter. Under microscope, it appears like irregular three dimensional brunches of grapes like cluster of cells. The colony pigmentation may vary from grey, grey white, grey white with yellowish to orange shades and in blood agar typical $\beta$ hemolysis may be produced; depending on the growth condition (Jahan et al., 2014). Abroad distribution of identical related $S$. aureus clones are responsible for the mastitis situations in Egypt with highly prevalence rate of methicillin resistance among the obtained isolates which represent an alarm for a great hazard to public health. (Ashraf et al., 2016; Ashraf, 2016). The use of antibiotics in farm management (growing crops and raising animals) has become a major area of concern. Its implications is the consequent emergence of antibiotic resistant bacteria (ARB) and accordingly their access into the human food chain with passage of antibiotic resistance genes (ARG) to the normal human intestinal microbiota and hence to other pathogenic bacteria causative human disease. Therefore, we pursued in this study to resistance determining region, mecA of , methicillin-resistant S.aureus (MRSA) (Osman et al., 2016). All S. 
aureus isolates were screened by PCR for mec $A$. $S$. aureus becomes methicillin resistant by the acquisition of the mec $A$ gene which encodes a penicillin binding protein (PBP2a) with a low affinity for $\beta$-lactamase. The strains producing PBP2a are resistant to all $\beta$-lactams (GarcíaÁlvarez et al., 2011). The Spa types were assigned via the Spa typing plugin. The staphylococcal cassette chromosome mec ( $\mathrm{SCCmec}$ ) types were determined by multiplex PCR as previously described . Representative isolates belonging to different Spa types were further analyzed by the Multi Locus Sequence Typing facility. (Harris et al., 2013, Ge et al., 2017).

The aim of this work directed to isolate, identify and detected the genes that causative agent from chicken farms were causing Bumble foot and from human samples were causing nosocomial infections at Giza and Cairo Governorate by using PCR Master Mix beside detection MRSA antimicrobial susceptibility pattern by using Vietk 2 system for these isolates.

\section{MATERIAL AND METHODS}

\subsection{Samples collection:}

A total of 160 samples from chicken and human were examined in Cairo and Giza Governorate for bacteriological examination. Samples pus from Bumble foot, Skin swabs in chicken and Diabetic foot swab, Skin sawb and Nasal swab in human were collected on $5 \mathrm{ml}$ nutrient broth in screw capped tubes in an ice box and transferred to laboratory for bacteriological examination .

\subsection{Bacteriological examination (Oxoid):}

Pre-enriched non selective medium (buffered peptone water) was inoculated with the collected samples at ambient temperature and then incubated at $37^{\circ} \mathrm{C}$ for $24 \mathrm{hrs}$ under aerobic condition.A loopful from incubated nutrient broth was streaked into:7\% salted nutrient agar; Baird parker agar; Mannitol salt agar and Blood agar. All plates were incubated for $24-48$ hours at $37^{\circ} \mathrm{C}$. The developed colonies were picked up and subcultured for purification. The purified colonies were morphologically identified by Gram stain and biochemical tests (Swayne, 1998).

\subsection{In-Vitro anti-microbial sensitivity test:}

The isolated MRSA strains were subjected to the sensitivity test against different antibiotics, using the Vitek 2 system (Chatzigeorgiou et al., 2011).

\subsection{Detection of resistance genes of isolated $S$. aureus:}

By using QIAamp ${ }^{\circledR}$ DNA Mini Kitinstructions (Catalogue no. M501DP100) (Sambrook and Russell David, 1989). It was applied on 8 random isolated MRSA ( mecA, blaZ, Spa) gene PCR was applied by using 8 sets of primers for detection of 8 resistance genes that may play a role in resistance of S. aureus. These genes were protein (spa), beta lactmase (blaZ), mecithicillin (mecA).

\section{RESULT}

\subsection{Total incidence of S.aureus from chicken and human:}

Staphylococci aureus isolated from human samples are higher than in chicken samples. That's to say of $66 \%$ chicken Skin swab, $10 \%$ of chicken bumble foot and $67.5 \%$ of the human nasal swab, $30 \%$ of the human Diabetic foot swab and $40 \%$ of the human skin swab were positive for S.aureus. Shown in Table (1)

\subsection{Incidence of MRSA among $S$.aureus isolated from chicken and human samples.}

MRSA isolates were higher in chicken samples than in human samples . 2 samples $(66.6 \%)$ of total 3 S.aureus from chicken Bumble foot and 9 (33.3\%) of total 27 S.aureus from human nasal swabs. In Table (2) stated that oxacillin, vancomycin, tetracycline, clindamycin, Doxycycline, Rifampicin and Erythromycin, were the most resistance antibiotics against the isolated staphylococcus aureus from chicken sample, on the other hand, Trimethoprim / Sulfamethoxazole, Moxifloxacin, Levofloxacin, Ciprofloxacin, Gentamicin, Nitrofurantoin, Tigecycline and Linezolid were the most sensitive (Table 3).

\subsection{Incidence of mecA, blaZ and spa gene from MRSA isolates of chicken and human samples by PCR.}

That mec A gene and Spa gene of MRSA isolates either from human sample were 5 positive, 1 negative and chicken sample were 1 positive, 1 negative by PCR and The percent of (mecA, Spa) gene PCR positive results were represented in $M R S A$ isolates of chicken origin $83.3 \%$. and MRSA isolates of human origin positive ( $\mathrm{mecA}$ ) gene were $83.3 \%$ while, the percent of MRSA isolates of chicken was $50 \%$. and shows that blaZ gene of $M R S A$ isolates either from all human sample were positive and all chicken sample were positive by PCR. and MRSA isolates of human origin positivess (blaZ) gene were 100\% while, the 
Table (1): Incidence of $S$. aureus from chicken and human sample

\begin{tabular}{|c|c|c|c|c|}
\hline \multirow[t]{2}{*}{ Origin } & \multirow[t]{2}{*}{ Type of sample } & \multirow[t]{2}{*}{ Total no.of samples } & \multicolumn{2}{|c|}{ Suspected $S$. aureus } \\
\hline & & & NO. & \% \\
\hline \multirow{3}{*}{ Chicken } & Pumple foot & 30 & 3 & 10 \\
\hline & Skin swab & 50 & 33 & 66 \\
\hline & Nasal swab & 40 & 27 & 67.5 \\
\hline \multirow[t]{3}{*}{ Human } & Diabetic foot swab & 10 & 3 & 30 \\
\hline & skin swab & 30 & 12 & 40 \\
\hline & TOTAL & 160 & 78 & 48.75 \\
\hline
\end{tabular}

Table 1: Incidence of MRSA S.aureus isolated from chicken and human samples.

\begin{tabular}{cccc}
\hline \multirow{2}{*}{ Type of Sample } & \multirow{2}{*}{ Total number of } & S. aureus isolates & \multicolumn{2}{c}{ MRSA } \\
& & NO. & $\%$ \\
\hline chicken Bumble foot & 3 & 2 & 66.6 \\
Human nasal swabs & 27 & 9 & 33.3 \\
Total & 30 & 11 & 36.6 \\
\hline
\end{tabular}

Table 2: The result obtained by using VITEK2 system(ultradiagnositic, bioMerieux complies with ISO13485 and FDA Quality System Regulation (QSR) ) for detection antibiotic sensitivity of S.aureus.

\begin{tabular}{lcccc}
\hline Antimicrobial & \multicolumn{2}{c}{ Chicken } & \multicolumn{2}{c}{ Human } \\
\cline { 2 - 5 } & MIC & Interpretation & MIC & Interpretation \\
\hline Oxacillin & $>=4$ & $\mathrm{R}$ & $>=4$ & $\mathrm{R}$ \\
Gentamicin & $<=0.5$ & $\mathrm{~S}$ & $>=16$ & $\mathrm{R}$ \\
Ciprofloxacin & 1 & $\mathrm{~S}$ & 4 & $\mathrm{R}$ \\
Levofloxacin & 2 & $\mathrm{~S}$ & 4 & $\mathrm{I}$ \\
Moxifloxacin & $<=0.25$ & $\mathrm{~S}$ & $>=8$ & $\mathrm{R}$ \\
Erythromycin & $>=8$ & $\mathrm{R}$ & $>=8$ & $\mathrm{R}$ \\
Clindamycin & $>=4$ & $\mathrm{R}$ & $>=4$ & $\mathrm{R}$ \\
Vancomycin & $>=32$ & $\mathrm{R}$ & $>=32$ & $\mathrm{R}$ \\
Doxycycline & $>=16$ & $\mathrm{R}$ & $>=16$ & $\mathrm{R}$ \\
Tetracycline & $>=16$ & $\mathrm{R}$ & $>=16$ & $\mathrm{R}$ \\
Nitrofurantoin & $>=16$ & $\mathrm{~S}$ & 32 & $\mathrm{~S}$ \\
Rifampicin & $>=32$ & $\mathrm{R}$ & $>=32$ & $\mathrm{R}$ \\
Trimethoprim Sulfamethoxazole/ & $<=10$ & $\mathrm{~S}$ & $<=10$ & $\mathrm{~S}$ \\
\hline
\end{tabular}

Table 3: Incidence of positive gene from MRSA isolates of chicken and human isolates by PCR.

\begin{tabular}{|c|c|c|c|c|c|c|c|}
\hline \multirow{2}{*}{ Type of isolate } & \multirow{2}{*}{ Total No.of examined isolates. } & \multicolumn{2}{|c|}{ mecA } & \multicolumn{2}{|c|}{ blaZ } & \multicolumn{2}{|c|}{ Spa } \\
\hline & & No. & $\mathrm{c} \%$ & No. & $\mathrm{c} \%$ & No. & $\mathrm{c} \%$ \\
\hline Human nasal swabs & 6 & 5 & 83.3 & 6 & 100 & 5 & 83.3 \\
\hline Chicken Bumble foot & 2 & 1 & 50 & 2 & 100 & 1 & 50 \\
\hline
\end{tabular}




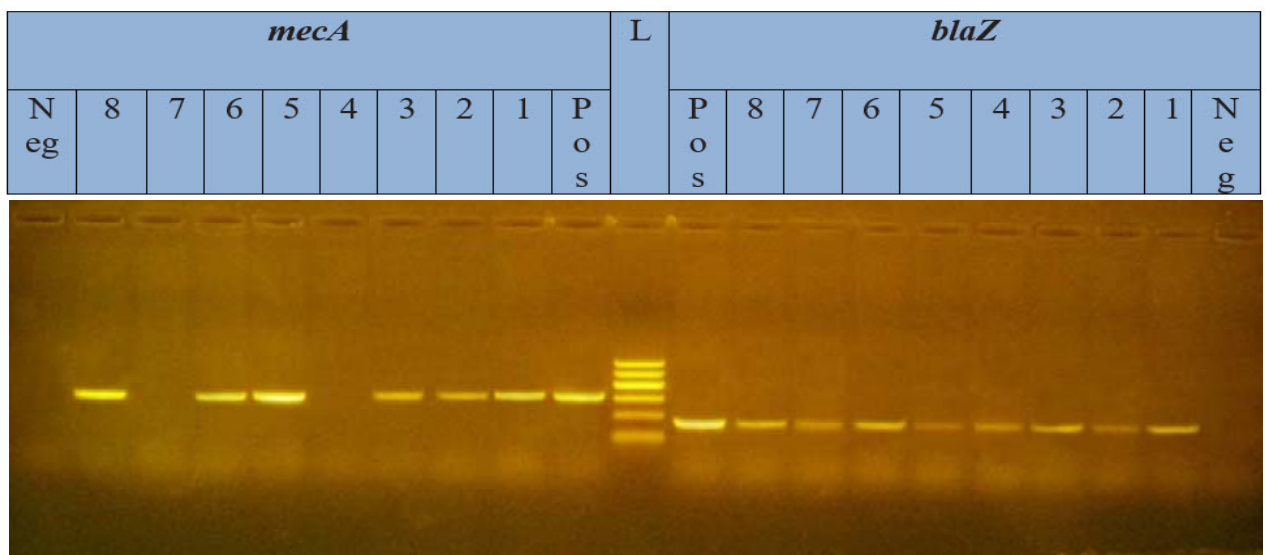

Figure (1): Agarose gel electrophoresis of PCR products after amplification of mecA gene at 310bp amplified product. Lane (L): 100-600bp DNA Ladder "Marker" (100 Pharmacia). lanes (1:3 , 5:6 , 8) positive isolates at $310 \mathrm{bp}$. and lanes $(4,7)$ : negative isolates at $310 \mathrm{bp}$. Lane Pos: Positive control (reference strain deposited to gene bank with MRSA ATCC 43300 methicillin-susceptible S.aureus ATCC 25923 ) . Lane Neg: Negative control and amplification of blaZ gene at 173bp amplified product. Lane (L): 100-600bp DNA Ladder "Marker" lanes (1:8) positive isolates.

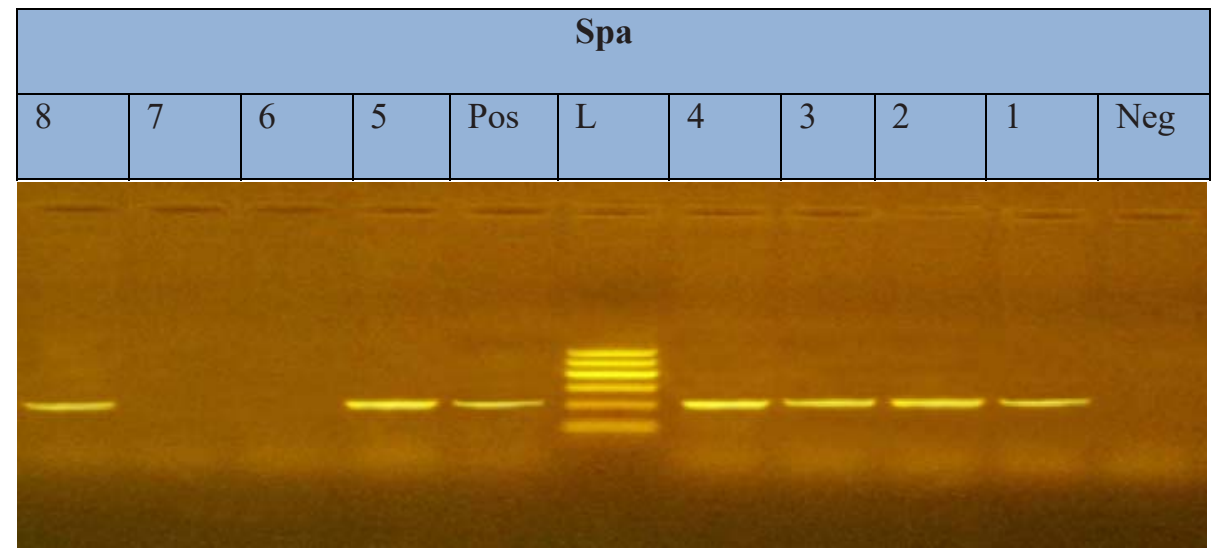

Figure (2): Agarose gel electrophoresis of PCR products after amplification of spa (IgG-binding protein) gene at 226 bp amplified product. Lane (L): 100-600 bp DNA Ladder "Marker" (100 Pharmacia). All lanes (1-5): positive isolates at $226 \mathrm{bp}$. Lane Pos: Positive control (reference strain deposited to gene bank with MRSA ATCC 43300 methicillin-susceptible S.aureus ATCC 25923 ). Lane Neg : Negative control and Lane 6-7: Negative isolate.

percent of MRSA isolates of poultry was 100\% (Table 4)

3.4. Detection of mecA and blaZ gene in MRSA isolates from chicken and human S.aureus :

Detected of mecA gene in a $310 \mathrm{bp}$, detected of blaZ gene in $173 \mathrm{bp}$ and detected of spa gene 226 bp in MRSA strains from poultry and human in positive samples (Figure 1, Figure 2).

\section{DISCUSSION}

S. aureus infection has become an increasingly grave problem in industrialized poultry farming.
Staphylococcal infections including, synovitis with arthritis,osteomyelitis, dermatitis, endocarditis, septicemia, wound infection and omphalitis (Lowder et al., 2009). Staphylococcus aureus in food is a consequence of inadequate hygienic handling and processing, posing a potential risk to public health. The current study aimed to characterize virulence factors, as well as antimicrobial resistance of Staphylococcus aureus and methicillin-resistant S. aureus (MRSA) isolated from retail chicken products and hand swabs from vendors in Egypt. In addition, genetic relatedness of the isolates from chicken and humans was evaluated by polymerase chain reaction-restriction fragment length 
polymorphism (PCR-RFLP) using protein $\mathrm{A}$ as a target. A total of 110 samples were collected from chicken products $(n=80)$ and vendors $(n=30)$. Overall, $30(37.5 \%)$ chicken products samples were positive for $S$. aureus, whereas hand swabs from meat handlers revealed that $18(60 \%)$ were positive. Ten MRSA strains were characterized by the presence of the mecA gene, comprising seven isolates from chicken and three from humans. Virulence-associated factors were evaluated by PCR, revealing that $31.3 \%$ of $S$. aureus isolates harbored the Panton-Valentine leukocidin (PVL) gene. This result was some what higher than that obtained by (El Bayomi et al., 2016).

These results disagreed with (Habeeb et al., 2014), A total of 90 (18.4\%) out of 489 (18.4\%) of the students were found to be colonized by S. aureus. Only $10(2.04 \%)$ of the students were found to be MRSA carrier. All MRSA isolates were sensitive to Vancomycin. PLV gene was detected in one MRSA strain. These results agreed with (ElJakee et al., 2008) A total of 409 samples were investigated bacteriologically to detect the occurrence of staphylococci among the diseased animals and human, the highest isolation rate was observed in human samples $(36 \%)$ followed by chicken $(12 \%)$ samples. A total of $78 \mathrm{~S}$. aureus isolates secured from different animals and human origins were characterized and identified using the most important conventional biochemical tests as anaerobic glucose fermentation, catalase, coagulase, acetone production, novobiocin sensitivity and mannitol fermentation. SpA was extracted from 17 S. aureus isolates (6 human and 2 chicken isolates). Concerning the human samples included in this study, 78 sample isolates Staphylococcus isolates out of 160 Total sample isolate, while only $11(36.6 \%)$ isolates were $M R S A$. whether MRSA is present in chicken from (2) sampled isolated out of (3) Staphylococcus isolates were $S$. aureus while only $2(66.6 \%)$ isolates were MRSA.

Staphylococci aureus isolated from human samples are higher than in chicken samples. That's to say, $66 \%$ of chicken Skin swab, $10 \%$ of chicken bumble foot and $67.5 \%$ of the human nasal swabs, $30 \%$ of the human Diabetic foot swab and $40 \%$ of the human skin swabs were positive for S.aureus.

In the current result of $M R S A$ from total isolates of chicken samples than in human samples. (2) samples (66.6\%) of total (3) S.aureus from chicken Bumble foot and (9) (33.3\%) of total (27) S.aureus from human nasal swabs. staphylococcus aures out (11) MRSA (36.6\%) this result can detected by antibiotic sesnsitivity Vitek 2 .
Status of the MRSA isolates and hence may have an impact on therapeutic approaches conducted to control infections due to such isolates. It is also possible that such additional genetic material increases the virulence of MRSA isolates. (Rushdy et al., 2007).

Added nosocomial pneumonia as an additional type of infection. Nosocomial infections with methicillin resistant Staphylococcus aureus (MRSA) became an infection control problem worldwide during the past 20 years. They are mainly associated with hospital associated, clonal lineages (HA-MRSA) which have a pronounced capacity for spread in and among hospitals . (Cuny et al., 2011)

The sensitivity tests for the isolated $S$. aureus showed strains indicated high resistance to methicillin followed by oxacillin; Nalidixic acid; Ampicillin; Amoxicillin; Cefotaxime and Tobramycin, respectively. Meanwhile, they were highly sensitive to Gentamycin; Enrofloxacin; Norfloxacin; Lomefloxacin and Ciprofloxacin. PCR results cleared that, femA; mecA and $h l b$ virulence genes were detected in all $5 S$. aureus studied strains (Ashraf, 2016).

\section{CONCLUSION}

Data presented in this study showed abroad distribution of identical related $S$. aureus clones are responsible for the resistance of antimicrobial situations in Egypt with highly prevalence rate of methicillin resistance among the obtained isolates which represent an alarm for a great hazard to public health.As bright as the future looks for new diagnostic tools, prospects concerning new developments of antistaphylococcal drugs for use in poultry \& human seem less encouraging.

\section{REFERENCES}

Ashraf A Abd El Tawab1, A., A. Maarouf2,Fatma I.ElHofy1, Aya A.El-Said3, 2015. Bacteriological studies on some food borne bacteria isolated from Chicken meat and meat products markted in Kaliobia Governorate. benha university mediacal Journal 29(2), 47-59.

Ashraf, A., Ahmad, M., Mokhtar, A.E.-H.S., Fatma, I.E., Hofy, H., Salem, S., 2016. Molecular characterization for some virulence and antibiotic resistance genes of Staphylococcus aureus isolated from dairy cattle's subclinical mastitis in EL-Sharkia Governorate. benha university mediacal Journal 30(1), 219-230.

Ashraf, A.A.E.T., 2 Ahmed, A. A. Maarouf, 1 Fatma I. El-Hofyand 3 Dina, H.Mousa, 2016. Bacteriological and Molecular studies on 
Methicillin-Resistant Staphylococcus aureus (MRSA) isolated from chicken meat and its products in Kaliobia Governorate. benha veterinary medical journal 31(1), 64-72.

Chatzigeorgiou, K.-S., Sergentanis, T.N., Tsiodras, S., Hamodrakas, S.J., Bagos, P.G., 2011. Phoenix 100 versus Vitek 2 in the identification of grampositive and gram-negative bacteria: a comprehensive meta-analysis. Journal of clinical microbiology 49, 3284-3291.

Cuny, C., Layer, F., Strommenger, B., Witte, W., 2011. Rare occurrence of methicillin-resistant Staphylococcus aureus CC130 with a novel mecA homologue in humans in Germany. PloS one 6 , e24360.

Osman, K., J. Badr, K. S. Al-Maary, I. M. Moussa, A. M. Hessain, Z. M. A. Girah, U. H. Abo-shama, A. Orabi and A. Saad, 2016a: Prevalence of the antibiotic resistance genes in coagulase-positiveand negative-Staphylococcus in chicken meat retailed to consumers. Frontiers in microbiology, 7.

El-Jakee, J., Nagwa, A.S., Bakry, M., Zouelfakar, S.A., Elgabry, E., El-Said, W.G., 2008. Characteristics of Staphylococcus aureus strains isolated from human and animal sources. Am Eurasian J Agric Environ Sci 4, 221-229.

El Bayomi, R.M., Ahmed, H.A., Awadallah, M.A., Mohsen, R.A., Abd El-Ghafar, A.E., Abdelrahman, M.A., 2016. Occurrence, Virulence Factors, Antimicrobial Resistance, and Genotyping of Staphylococcus aureus Strains Isolated from Chicken Products and Humans. Vector-Borne and Zoonotic Diseases 16, 157-164.

García-Álvarez, L., Holden, M.T., Lindsay, H., Webb, C.R., Brown, D.F., Curran, M.D., Walpole, E., Brooks, K., Pickard, D.J., Teale, C., 2011. Meticillin-resistant Staphylococcus aureus with a novel mecA homologue in human and bovine populations in the UK and Denmark: a descriptive study. The Lancet infectious diseases 11, 595-603.

Ge, B., Mukherjee, S., Hsu, C.-H., Davis, J.A., Tran, T.T.T., Yang, Q., Abbott, J.W., Ayers, S.L., Young, S.R., Crarey, E.T., 2017. MRSA and multidrug-resistant Staphylococcus aureus in US retail meats, 2010-2011. Food Microbiology 62, 289-297.

Habeeb, A., Hussein, N.R., Assafi, M.S., Al-Dabbagh, S.A., 2014. Methicillin resistant Staphylococcus aureus nasal colonization among secondary school students at Duhok City-Iraq. Journal of Microbiology and Infectious Diseases vol 4215 230.

Harris, S. R., E. J. Cartwright, M. E. Török, M. T. Holden, N. M. Brown, A. L. Ogilvy-Stuart, M. J. Ellington, M. A. Quail, S. D. Bentley and J. Parkhill, 2013: Whole-genome sequencing for analysis of an outbreak of meticillin-resistant Staphylococcus aureus :a descriptive study. The Lancet infectious diseases, 13, 130-136.
Jahan, M., Rahman, M., Parvej, M.S., Chowdhury, S.M.Z.H., Haque, M.E., Talukder, M.A.K., Ahmed, S., 2014. Isolation and characterization of Staphylococcus aureus from raw cow milk in Bangladesh. Journal of Advanced Veterinary and Animal Research 2, 49-55.

Köck, R., Schaumburg, F., Mellmann, A., Köksal, M., Jurke, A., Becker, K., Friedrich, A.W., 2013. Livestock-associated methicillin-resistant Staphylococcus aureus (MRSA) as causes of human infection and colonization in Germany. PloS one 8, e55040.

Lowder, B.V., Guinane, C.M., Zakour, N.L.B., Weinert, L.A., Conway-Morris, A., Cartwright, R.A., Simpson, A.J., Rambaut, A., Nübel, U., Fitzgerald, J.R., 2009. Recent human-to-poultry host jump, adaptation, and pandemic spread of Staphylococcus aureus. Proceedings of the National Academy of Sciences 106, 1954519550.

Rushdy, A.A., Salama, M.S., Othman, A.S., 2007. Detection of methicillin/oxacillin resistant Staphylococcus aureus isolated from some clinical hospitals in Cairo using Meca/Nuc genes and antibiotic susceptibility profile. Int J Agric Biol 9, 800-806.

Sambrook, J., Russell David, W., 1989. Molecular cloning: a laboratory manual. Vol. 3. Cold spring harbor laboratory press.

Suleiman, A., Zaria, L., Grema, H., Ahmadu, P., 2013. Antimicrobial resistant coagulase positive Staphylococcus aureus from chickens in Maiduguri, Nigeria. Sokoto Journal of Veterinary Sciences 11, 51-55.

Shan, W., J. Li, Y. Fang, X. Wang, D. Gu and R. Zhang, 2016 :Rapid Identification of MethicillinResistant Staphylococcus aureus (MRSA) by the Vitek MS Saramis system. Current microbiology, 72, 29-32.

Perez-Roth, E., F. Claverie-Martın, J. Villar and S. Mendez-Alvarez, 2001: Multiplex PCR for Simultaneous Identification of Staphylococcus aureus and Detection of Methicillin and Mupirocin Resistance. Journal of clinical microbiology, 39, 4037-4041 